\title{
Knowledge Management-Enabling Technologies: A Supplementary Classification
}

\author{
Monika Dávideková ${ }^{1}$, Michal Greguš ${ }^{1}$, Marek Zanker ${ }^{2}$ (D), Vladimír Bureš 2 (D)
}

\begin{abstract}
Scientific and technological developments in informatics enable intensive transformation of data into valuable information. Enriched with context, information may be turned into knowledge, allowing organizations to optimize their processes and profile themselves as learning knowledge organizations. Several classifications of knowledge and knowledge management are available in scientific literature and research publications. In this paper the implementation and application of information and communication technology in knowledge management is being assessed from the perspective of synchrony and mutual interaction among collaborating parties. Following the PRISMA scheme, a systematic review procedure using Scopus and Web of Science databases was conducted. Obtained manuscripts underwent manual content analysis. The outcome of this analysis represents the classification of widespread ICTs into diverse categories based on extensive literature research. It specifies an original type of classification by connecting intertwined synchronicity and interaction as the main classification criteria, and it provides examples of commonly used ICTs in business practice. The introduced classification aims to deepen the comprehension of ICTs, which may lead to improved efficiency and/or eligibility of technological implementations and applications of knowledge management based on the undeniably enormous benefits of the use of ICTs in processing of business operations.
\end{abstract}

Keywords: Knowledge Management, Information and Communication Technology, Classification, Knowledge, Synchrony, Interaction.

\section{Introduction}

Communication has always been the core of most human interaction. With the beginning of the current digital era, information and communication technology (ICT) was developed that is today the most vastly used means of communication besides the spoken word. ICT allows not only communication, but also automated capturing of data, its storing and fast processing. The increased speed of information exchange enabled by the rise and advancement of ICT has brought revolutionary changes to the way people work, communicate, learn, spend their free time, stay in contact with family members and friends and interact with communities (Jorgenson \& Vu, 2016). It has bolstered productivity with significantly higher efficiency than

\footnotetext{
${ }^{1}$ Department of Information Systems, Faculty of Management, Comenius University,

Odbojárov 10, 82005 Bratislava, Slovakia

${ }^{2}$ Department of Information Technologies, Faculty of Informatics and Management, University of Hradec Králové,

Rokitanského 62, 50003 Hradec Králové, Czech Republic

$\bowtie$ vladimir.bures@uhk.cz
} 
any of the earlier technologies (Hidalgo Pérez et al., 2016). No other technology has had such a global impact on such a high level as ICT in recent decades (Al-Rodhan, 2011).

Communication is an essential process for business and a very important working dimension in virtual environment (Gonçalves et al., 2014). Even more in times of a pandemic when business activities must be performed at a distance, in conditions of distributed staff. People connect with each other over the internet to exchange information and execute their daily business activities. ICT provides the basis for computer applications to execute business processes, ranging from highly-specialized activities such as failure prediction (Borkowski et al., 2019) to specific tasks like design and development of business rules (Kluza \& Nalepa, 2020). Communication is currently carried out by means of ICT transmitting visual and audio signals. A video conference provides the live image and voice of the communicating parties, so that they can receive and respond to each other's reactions to successfully steer the conversation. It imitates real personal communication by transmitting picture and tone.

Mobile cellular, computer and telecommunication technology are the dominant drivers of output per worker, capital per worker, and hence have relatively significant contributory power to initiate, support and uphold long-term economic growth (Kumar et al., 2016). ICT currently offers a broad spectrum of possibilities for human communication, performing business activities, learning or spending leisure time. It irreversibly modified the way we live, interact, perceive and imagine. ICTs have already become a substantial part of our life.

This paper aims to add a supplementary classification of ICT in the realm of knowledge management in business organizations. It describes an extensive research performed by analyzing the ICT application possibilities in knowledge management that have been applied so far. This paper introduces a classification of the assessed ICTs by dividing them into categories based on their attributes. It intends to enhance the actual perception of assessed ICTs in order to facilitate a more efficient application and implementation of available communication technology that may foster the execution of business activities by supporting smoother collaboration and human interaction and contribute to team cohesion. The main purpose of the conducted research endeavor described in this paper is to inspire future research on the possible applications of ICT in the knowledge management domain by creating and proposing innovative application concepts. In addition to that, this paper also intends to advance future understanding in the field of ICT application, its implementation in business organizations and its impact on human interaction.

All topics and ideas presented in this study represent an extension of the considerations and discussions undertaken in a paper presented by the authors at the Hradec Economic Days conference in 2020 (Davidekova et al., 2020). The paper is organized as follows: The next section describes diverse applications of ICT in various areas of knowledge management identified in business organizations. It discusses the potential impediments and opportunities for current and future exploitation of the utilization of ICTs in the field of knowledge management. The subsequent section classifies the known and currently utilized ICTs in business organizations into classification categories established on the basis of findings from previous sections. The provided classification aspires to deepen the understanding of ICTs in order to increase the efficiency of their implementations in the field of knowledge management in business processes. Last but not least, the conclusion summarizes the outcomes of the research described in this paper. 


\section{ICT in Business Operation Processes}

In current work life, people interact on a daily basis through software applications to process data in order to gain information and to carry out work tasks. They benefit from the immense possibilities offered by information and communication technology that enables performing faster and where appropriate also automated processing through demanding computations that would otherwise be tedious and often also boring work. Working with text processors, spreadsheets, specialized software applications, sending electronic mail, calling everywhere at any time by using of mobile phones and various other applications of ICTs became a substantial part in all spheres of our everyday life: at work, at school and at home. Business companies, non-profit associations and governmental organization structures rely on IT solutions to support their operations with faster processing of data than was ever possible before the development of digital information and communication technology. With further development and progress of ICT and artificial intelligence, the automated processing of data evolved. ICT is not a mere enabler of conducting operations anymore (Cherbakov et al., 2005). From the business point of view, ICT drives business strategy, enables access to new markets and creates new opportunities.

ICT has been widely applied in the field of knowledge management, which can be understood as the process of identification and utilization of collective knowledge in an organization to help the organization compete (Alavi \& Leidner, 2001). This process comprises various activities associated with specific knowledge processes reflecting the knowledge life cycle, i.e. activities with focus ranging from knowledge creation or identification to its usage or substitution. Several of those have gained extensive popularity as instruments for knowledge management, as evidenced by existing studies. For instance, Jarmooka et al. (2020) map individual ICTs to selected knowledge management processes. These remarkable technologies gained immense interest due to their potential for systematizing, facilitating, and expediting company-wide knowledge management.

ICT can enhance knowledge sharing by lowering temporal and spatial barriers between knowledge holders and workers, and generally improve access to knowledge (Hendriks, 2001). ICT implemented in knowledge management denote organizational knowledge management system (Huysman \& de Wit, 2004; Maier \& Hädrich, 2011) The main objective of knowledge management systems is to support the creation, sharing, storage and application of knowledge in organizations (Alavi \& Leidner, 2001). For every organization which intends to start with knowledge-related initiatives, it is important to store the gathered knowledge of research and development initiatives to be able to further utilize the outcomes that were achieved tediously and at great cost, to prevent reinventing the wheel or failing to meet goals by making the wrong assumptions. It is important to collect operational experience from the field of product usage to innovate the product. ICT can also be used for monitoring, which may lead to process optimization. Furthermore, big data analysis can extract new information from large bulks of data that would otherwise not be computable due to human limitations (Farrasis et al., 2019; Chierici et al., 2019).

ICTs allow access to information and knowledge through computers or mobile devices. They are used for knowledge management in the form of infobase, knowledge base, network, electronic rapports, knowledge mapping, Lotus Notes and other databases, digital discussion platforms etc. The technological perspective in knowledge management comprises ICTs utilized as expert resource planning systems, executive information systems, expert systems, intelligent agents, multimedia, search engines and smart systems, computer resident knowledge repositories, data mining, data bases and warehouses (Davidekova et al., 2020), 
programmed logic routines on computational machinery and on data residing in data warehouses, use of email or group support systems, codification approach within a central repository holding knowledge classified in categories such as programming bugs, quality control reports, new developments (Desouza, 2003), ticketing systems, manuals, World Wide Web, the Internet, intranets (O'Leary, 1998), Wikis (Raman et al., 2005) and other knowledge catalogues.

Research in the field of knowledge extracted from data stored in databases and data warehouses through mining questioned anew the efficiency of the method of storing and accessing data (Costa et al., 2000; Han et al., 2012; Inmon, 2005; Pavlo et al., 2009; Reddy et al., 2010; Taylor et al., 2015). These analyses also created new concepts and perspective on the perception of knowledge, information and data connections. They confirm Tuomi's insight proclaiming the need of prior knowledge before the collection of data to determine which data to store (Tuomi, 1999). This is essential for software development during requirements engineering, as the settings for data capturing are to be known prior to architecture design and concept phase, which includes e.g. the logging aspect for bug and root cause analyses and debugging of software (Chinta \& Das, 2005; Chuvakin \& Peterson, 2010; Marty, 2011; Suneetha \& Krishnamoorthi, 2009). By deciding which data to capture and log, further search for additional information can be carried out. This confirms Tuomi's premise that data emerges only after we have information, and that information emerges only after we already have knowledge (Tuomi, 1999). In other words, prior knowledge may lead to the emergence of new information (Dávideková \& Greguš, 2016; Alavi \& Leidner, 2001).

\section{Methodology}

The classification provided in this paper is based on the following procedure. First, papers associating ICT with knowledge management initiatives were identified. PRISMA scheme was used as a guiding tool. The identification process was done by searching for keywords "ICT and knowledge management", "knowledge management systems" and "classification and ICT and knowledge management" in the scientific databases Scopus and Web of Science. This scientific database was the primary source of the studies and research papers that were investigated. The only primary filter applied was an endeavor not to include papers focusing on the integration of ICT into enterprises, data-warehouses and data mining, which represented the majority in the returned set of materials during initial scanning. The reason is that many identified papers dealt with technologies as such and were rarely associated with knowledge management initiatives.

Moreover, only papers labelled as articles were selected. As it is apparent, Scopus includes a great number of papers published in conference proceedings. As journal articles reach a higher level of quality, conference proceedings were excluded from the search outputs. Second, screening and reduction of the source set of scientific publications was further performed by extending the keywords in Scopus and both language and open access availability in both databases. It makes sense to include only studies written in English and studies that can be assessed during content analysis. Thus, open access was selected as the appropriate paper attribute. Third, the relevancy of published studies was considered. Manuscripts form the field of studies such as material science, veterinary medicine, polymer technology, endocrinology, astronomy or planetary science were excluded. The whole process is depicted in Figure 1. Fourth, all remaining manuscripts underwent manual content analysis. 


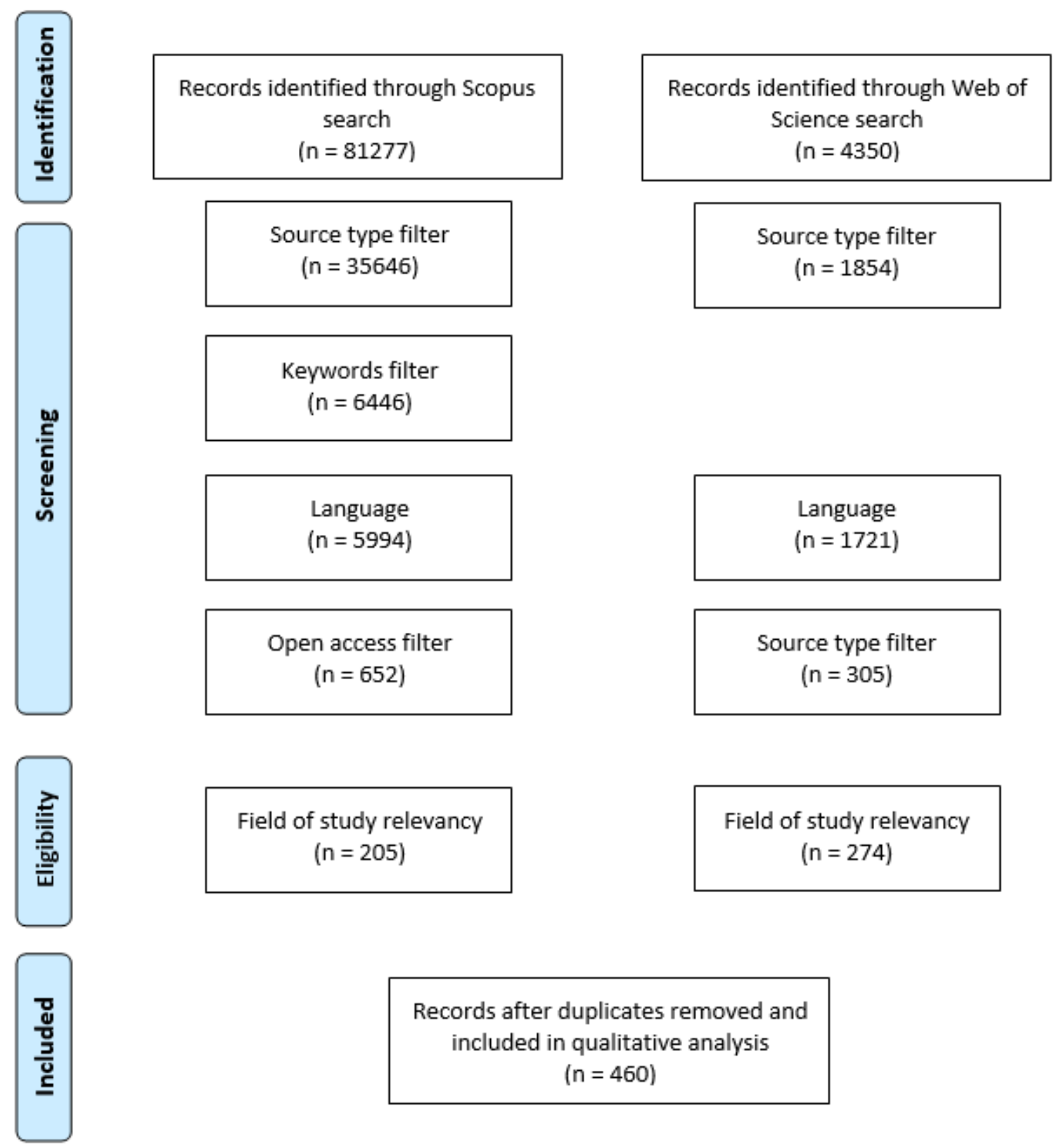

Fig. 1. PRISMA flow diagram. Source: Authors.

\section{Overview of Classifications of ICTs in Knowledge Management}

This section focuses on various classifications of ICTs used in knowledge management. The analyzed classification categories were divided into the individual subsections of this section for a greater convenience of the reader. The classifications provided in research papers so far described in first subsection led to the development of the classification of ICT in knowledge management introduced in this paper. 


\subsection{Classification of ICT Based on the Type of Transferred Knowledge: Tacit versus Explicit Knowledge}

Organizational knowledge is generally classified into two categories based on the easiness or difficulty with which it can be externalized: explicit knowledge and tacit knowledge (Lin et al., 2008; Battistutti \& Bork, 2017). The term explicit knowledge represents knowledge that is codified (Levin \& Cross, 2004), expressed, documented, told or externalized on a different way than as it is known, in order to represent valuable information. Explicit knowledge can be relatively easily formulated by means of letters, numbers or other symbols and therefore can be effortlessly digitalized and captured. Documented and recoded knowledge can be transferred to and shared with others relatively easily, e.g. by the use of information technology (Johannessen et al., 2001).

From the technological perspective, systems dealing with explicit knowledge comprise knowledge-based systems such expert systems, recommending systems or decision-support systems. All types of these software applications possess a knowledge model that enables the provision of outcomes required for taking an action. Expert systems technology is able to deliver mechanisms for building the institutional or corporate memory of a firm. The rulebased mechanism tends to be associated with the expression of explicit knowledge in the form of formal rules that are processed by the system. Similarly, case-based reasoning systems enable providing support based on similar cases which happened in the past. Regardless of the type of knowledge system, explicit knowledge always has to be transformed into a specific type of automatically processable format (Tan et al., 2016).

Highly specialized approaches and techniques are used when dealing with explicit knowledge, such as integrated analytical hierarchy process, quality function development and multichoice goal programming method (Liao \& Kao, 2014), ontology (Takhom et al., 2018), multiagent systems (Alfonso-Cendon et al, 2016) or Bayesian learning (Boluki et al., 2017). On the other hand, the term tacit knowledge denotes the type of knowledge that is difficult to codify or explain (Levin \& Cross, 2004) and very often is not even known to represent important knowledge. Tacit knowledge is frequently represented by skills (Foray \& Lundvall, 1998; Johannessen et al., 2001) and experience. This type of knowledge is highly personal, contextspecific, and therefore hard to formalize and communicate (Woo et al., 2004). The implications for the application of ICT are apparent. While formalized or documented explicit knowledge is easy to share and manage by using information and communication technologies (Selamat \& Choudrie, 2004), tacit knowledge cannot be represented by an appropriate format or scheme. There has been a dispute among researchers whether information technologies are capable of supporting tacit knowledge work at all (Panahi et al., 2012).

Hence, certain types of knowledge-sharing technologies enabling indirect influence of tacit knowledge are more frequently designed and developed. For instance, information or communication technologies focused on peer-to-peer communication, social media or networking supporting social interaction, experience sharing, observations or informal relationships are widely implemented. Many techniques and methods are used in these systems, for instance the development of conceptual models (Raudeliuniene and Davidavicius, 2017), monitoring social network activities (Chung and Liang, 2020) or the establishment of virtual communities of practice (Babajani-Vafsi et al., 2019), to name a few.

Based on the definitions of tacit and explicit knowledge mentioned above, it could be concluded that the knowledge transferred by means of ICT comprises only explicit knowledge. Thus, this would mean that no tacit knowledge can be transferred using ICT. This 
is the conclusion that was reached and confirmed through research by scientists who proved that tacit knowledge is mainly transferred by non-ICT methods, whereas explicit knowledge can be transferred via various combinations of methods (Nguyen \& Burgess, 2014). This would mean that tacit knowledge cannot be transferred by ICT by any means. However, this conclusion is mostly associated with researchers form the pre-social web era (Panahi et al., 2012). Another research already showed and concluded that tacit knowledge, too, can be transferred by means of ICT, e.g. by video records (Linde, 2001; Nonaka \& von Krogh, 2009), video conferences, over the phone and by email (Smith, 2001), audio transmission or visual transmission, desktop sharing, etc.

Considering the mentioned types of data transmission and sensual perception, we can conclude that picture and voice are accompanied by tacit knowledge that is not even recognized as representing knowledge and therefore is missing in explicit knowledge. Thus, tacit knowledge, too, can be transferred using ICT for communication. Considering these research findings, ICTs could be classified into the following classification categories: ICT enabling transfer of explicit knowledge and ICT allowing transfer of tacit knowledge. However, there are exceptions. For instance, Maravilhas and Martins (2019) present a digital environment Fab Labs, which enables work with both explicit and tacit knowledge.

\subsection{Classification of ICT Based on Technological Differences}

ICT has attracted the attention of several researchers who have been analyzing and investigating the impact and effects of these technological means on communication from various perspectives. Diverse classifications of ICT emerged. Another categorization of ICTs that can be obtained by studying scientific publications is a classification of ICTs utilized in knowledge management by dominant technology. In other words, the technology on which the knowledge management system is built on. In the past, various review papers (Alavi \& Leider, 1999) analyzed ICT systems applied in knowledge management by differentiating the front-end and back-end architecture, the programming language, and the possibilities of capturing and representing the collected knowledge.

Through excessive technological assessment of the majority of knowledge management systems currently used in organizational structures, it can be concluded that they are based on multiple combinations of the following technologies: representation of data in browsers or other applications for front-end visualization, electronic mail, search and retrieval tools, data repositories like databases and data warehouses, www servers, agents and filters, external server services, archives of processed tasks, chronicles of collected solved incidents or undergone workarounds, closed tickets, documentations of bug fixing, visual and/or audial records, videoconferencing, speech-to-text and/or text-to-speech synthetizing, artificial intelligence with picture processing or audio comparison, etc.

The more popular, widely used, and freely obtainable the technology, the higher the probability of wide usage by population (Constantinescu, 2015; Rashid et al., 2019). The higher the number of possible contributors, the broader the set of knowledge that can be captured, collected, and stored. However, besides these undeniable and significantly impacting aspects, the ease of use (user-friendliness in other words) determines whether a technology will be used or not. Search engines with automatic completion and population of possible keywords are easier to use than catalogues where the user must know the whole tree of categories in order to reach what he/she is searching for. Analogically, a full text search that examines the whole texts of all stored records is easier to use in comparison with keyword search of articles with category labels only. The more intuitive and simpler the use with less clicking, the more participation of broad public can be achieved. One of the first 
open public and widely spread initiatives is the project Wikipedia (Völkel et al., 2006, Krötzsch \& Vrandecic, 2009), which is an open encyclopaedia where everyone can become a contributor. This is based on a database system, world wide web, or full text search engine. Since its birth on January 15, 2001, it has grown to be the world's largest reference website with more than 53 million articles in more than 300 languages and attracting more than 1.5 billion unique visitors monthly. In addition to the WikiMedia project, various other projects are now publicly available, such as Wikibooks or WikiVersity (Nancy et al., 2019). The framework for creating own private Wiki is an opensource project, too, as it helps organizations to capture, gather and organize the organizational knowledge spread across the population in a way that is known to the majority of the current workforce. In addition to this well know framework, several companies developed their own layout and presentation layer for the same purpose: to capture, store and manage information by various contributors. Technologies similar to Wiki include SharePoint, Confluence by Atlassian, Nuclino, Notion, Guru, Jive, Dropbox Paper, Google Suite, Knowledge Owl etc.

Similar technology to Wiki framework can be represented by ITIL systems like Ticketing systems such as Jira from Atlassian, OTRS, SystemNow, Microsoft System Center, LiveZilla, or Help Desk. These systems gather information by recording data for each occurrence coming as a task to the input gate. The whole processing information is stored for future reference and can be used for data mining.

Furthermore, during the development of scanners, sensors and various methods for labelling products for sale, several identification methods were developed, such as European Article Number (EAN) codes or Quick Response (QR) codes, for an automated processing of captured data. Usually a hyperlink with further information is crypted into a line code (EAN) or a matrix code $(\mathrm{QR})$ that can be easily scanned by a sensor or nowadays also a smart device with a camera (e.g. smartphone) and internet access. After reading the code, a browser window opens with information about the given product. A similar utilization of ICT can be found in logistic companies for delivery tracking, or in cultural facilities like museums or galleries with information about an exhibit or display. Last but not least, QR codes are currently often used for augmented reality where a virtual object with information is shown, if appropriate, on the display after scanning the QR code.

In the previous decade, several initiatives emerged that focused on artificial intelligence for automated recognition of pictures or audio records. Such applications range from recognition and identification to speech-to-text and text-to-speech synthesis. There are many examples of technologies for objects identification based on picture processing, for instance the software application with artificial intelligence for plant recognition Pl@ntNet (Goëau et al., 2014) available online through internet browsers or on smartphones and handheld devices with Android or iOS operation systems; mushroom identification (Simon, 2013) as a software application on Android devices; or other life identification initiatives for which an international annual conference LifeCLEF is organized. As an example of speech-to-text and text-to-speech synthesis, we can name Google translate, which allows to record speech in one language, then processes this with speech-to-text synthesizer to acquired text and translates this to another language and then provides the option of synthesizing the obtained text into speech by robotic synthesizer. All that with only a few taps of a finger on a smart handheld device like the smartphone that almost always accompanies us. It is easy to use and widespread, built on a large amount of data in the background and broadening its resources for refining the identification algorithm with each use. 


\subsection{Focusing on Interaction and Synchronicity in Communication through ICT}

The classifications described so far have provided mostly insights already presented in other studies. This section brings a supplementary classification of existing technologies, which was defined as the main aim of this study. By analyzing which technological innovations spread fast and to a vast number of users under the premise of being available, affordable and easy to use, it can be concluded that the more interaction and the more ways of sensual perception are integrated, the more and faster the technology spreads. Therefore, we decided to assess the currently used ICTs by focusing on the aspect of interaction and synchrony of reactions described in this section. As has already been confirmed by the extensive research of various researchers, learning by doing is the most memorable way of acquiring a new skill, as the highest possible amount of sensual perception is involved in the transaction. A human remembers approximately $10 \%$ of read text, $20 \%$ of heard narration, $30 \%$ of seen or visually perceived stimuli, $50 \%$ of combined audial and visual stimuli, $70 \%$ of narration performed by himself/herself and $90 \%$ of combined narration carried out by himself/herself and action executed by himself/herself (Hroník, 2007).

This only confirms that incorporating more senses into information intake relates to higher understanding and memorization. This is why people memorize more by watching and seeing than by reading (Aitken, 1994; Mattingly, 1972). In other words, according to the results of extensive research in the field of learning, we learn best by doing (DuFour et al., 2006), and thus, the most effective way to teach someone how to do something is to let him/her do it (Schank et al., 1999). In this way, the learning person uses their cognitive skills to consciously follow explicit knowledge and at the same time, often unconsciously, applies his/her tacit knowledge gathered from previous experience in his/her life by reacting to present circumstances and situations. Reading or listening requires a large amount of conscious focus and concentration in order to remember explicit knowledge and, if applicable, only little tacit knowledge processing.

The tacit information transferred in such a case entails visualization of shapes, colors and/or motions of pictures, perception of human body (posture, gestures, mimic, non-verbal communication) or other visual stimuli and/or audial information the heard voice (volume, rate, pitch, fluency, articulation, tone). The difference between memorizing explicit knowledge and the practical "learning by doing", which also includes processing tacit knowledge, becomes greater in the process of simulation (Aldrich, 2005). Simulations make it possible to learn by doing without having to wait for a specific occasion or without making it stressful for the learner. Simulations may work in practice, even though they certainly do not work in theory (Aldrich, 2005).

Theoretically, we would expect that learned explicit knowledge is performed without any mistake. However, in practice the human mind conveys not only the learned explicit knowledge, but also the processes inherited with tacit knowledge from previous experience, and therefore the person may behave differently. Unconscious reactions based on intuition and tacit knowledge are often processed by the limbic system and the amygdala. These parts of the neural network frequently process neural stimuli by inducing emotions of various intensity and actions based on felt emotions. The more successfully and positively a reaction to a felt emotion and perceived stimuli has been perceived in the past, the faster, more unconsciously, more automatically will the action be performed. However, the frontal cortex of the human brain allows conscious processing of explicit information and knowledge even at such times. Simulations virtualize situations with corresponding circumstances for the action that is to be executed; the learner experiences a repeatedly required sequence of actions 
and learns what is deemed to be wrong by discovering the consequences of ae action. Simulations represent a safe way of learning by doing that can be recorded, assessed and repeated (Dávideková \& Hvorecky, 2017).

The classification provided in this paper focuses on the aspects of interaction and synchronicity, as the synchrony of feedback immediately supports or suppresses the performed action for future execution. These classification aspects were chosen on the basis of the learning by doing facet which enables synchronous practice with necessary interactive participation of the learner. The two dimensions of the proposed classification of synchrony and interaction divide the plane into four quadrants: from passive and asynchronous, over synchronous and passive, and asynchronous and actively interactive, to synchronous and actively interactive from the point of view of the communicating parties and the utilized ICT.

As mentioned above, the synchronous feedback allows future support or suppression of a performed action and also enables incorporating the transferred tacit knowledge and unconscious processing of it and thus operationally changing the actions which are to be performed subsequently in the given transaction. However, the asynchronous mode allows incredible flexibility (Wheeler \& Fournier, 2001) in transactions and knowledge transfer. Asynchrony is therefore considered to be a significant factor of ICT utilization in organizations.

These two facets (synchrony and interaction) put on axes to divide the plane into 4 quadrants are depicted in Figure 2. ICT Technologies associated with particular quadrants of the proposed classification are provided in Table 1. Considering these 2 classifying facets (creating 4 categories), all of the above-mentioned ICTs can be assigned into these categories.

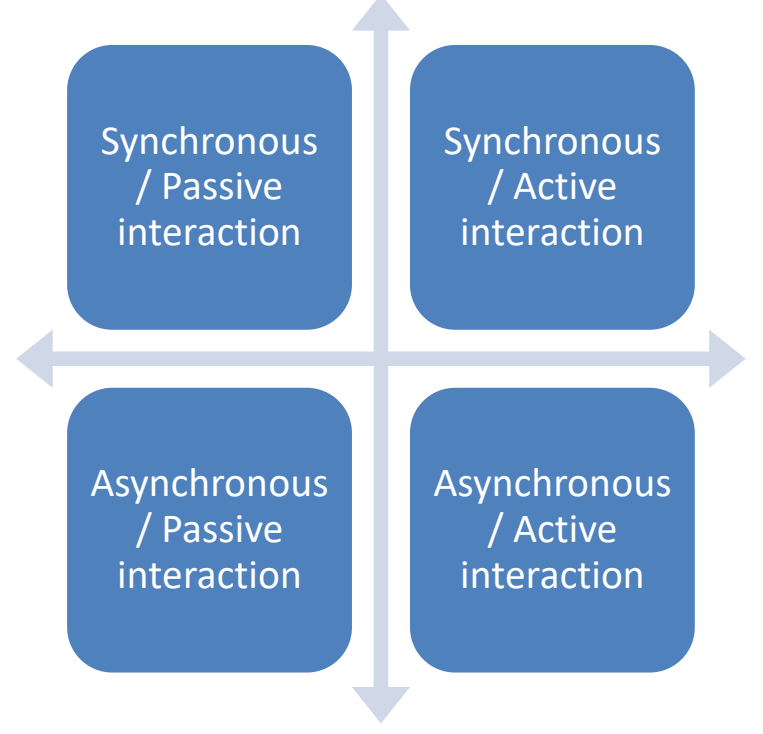

Fig. 2. Four Quadrants of ICT Classification. Source: Authors. 


\begin{tabular}{|c|c|}
\hline Quadrant & ICT focused on \\
\hline $\begin{array}{l}\text { Asynchronous, } \\
\text { Passive Interaction }\end{array}$ & $\begin{array}{l}\text { Infobase, knowledge base, mobile knowledge base, network, electronic } \\
\text { rapports, knowledge mapping, Lotus Notes, expert systems, intelligent agents, } \\
\text { computer resident knowledge repositories, database, data mining, data } \\
\text { warehouse, big data, routines that are programmed in the logic of } \\
\text { computational machinery and on data residing in data storages, use of email } \\
\text { or group support systems, codification approach, in which a central repository } \\
\text { contains knowledge in categories such as programming bugs, quality control } \\
\text { reports, new developments, World Wide Web, Wiki. }\end{array}$ \\
\hline $\begin{array}{l}\text { Asynchronous, } \\
\text { Active Interaction }\end{array}$ & $\begin{array}{l}\text { Internet, Intranet, Search engines, Smart systems, Artificial intelligence } \\
\text { systems, chats like MS Teams, Skype for Business etc. }\end{array}$ \\
\hline $\begin{array}{l}\text { Synchronous, } \\
\text { Active Interaction }\end{array}$ & $\begin{array}{l}\text { Digital discussion platforms, Virtual reality, Augmented reality, Artificial } \\
\text { intelligence systems, chats like MS Teams, Skype for Business etc., phone } \\
\text { and video conferences }\end{array}$ \\
\hline $\begin{array}{l}\text { Synchronous, } \\
\text { Passive Interaction }\end{array}$ & Multimedia (Video record, Sound record), Sharing \\
\hline
\end{tabular}

Tab. 1. Classification of mentioned ICT in specific quadrants. Source: Authors.

As can be seen in the Table 1 and retrieved from the aforementioned sections, most currently utilized ICTs in the field of knowledge management represent passive, asynchronous technology without interaction for the end user that conveys explicit knowledge. Such technology mostly comprises only data, information, or knowledge sources. Similar are also Manuals, HowTos or even Newsletter etc. in companies.

Furthermore, when observing daily working life in organizations, far more uses of ICTs can be found than only those mentioned in the cited articles or in the sections above.

The second quadrant with category specification 'synchronous and actively interactive' refers to "learning by doing". It represents the internalization of learned information through experience. Table 1 lists ICTs that require active interaction of the end user, e.g. simulationbased software applications or modelling tools (Otčenášková et al., 2011). They create space for the end user to ask questions, for the lecturer/leader to repeat actions and transfer tacit knowledge in this way (Aldrich, 2005; DuFour et al., 2006; Wheeler \& Fournier, 2001). Similarly, participating in training in virtual or augmented reality allows the learner to actively manipulate virtual objects as he/she would do in physical reality (Dávideková et al., 2017). In this way, the user repeatedly utilizes multiple sensory receptors (touch, sight, hearing, etc.), which supports the learning process by increasing memorization rate.

Modern innovative technologies usually integrate multiple representation techniques to attract the attention of the end user and to make it more convenient for the reader. For instance, the combination of text, pictures, videos and sounds are common integral parts of communicators or instant messaging programs. Smileys, colorful highlighting of unread messages or indication of the current status of a communication partner by text and color can serve as another frequently applied example. Furthermore, notification sounds for new messages etc. Such interactive, colorful, and synchronous systems attract the end user's attention via multiple sensual receptors and enhance user experience. All this is already perceived as a must have. All the symbols, sounds and pictures (e.g. smileys) already convey information and knowledge. People behave according to them, they unconsciously and intuitively process the newly perceived information by the rules that emerged from previous experience, e.g. 
when a contact is inactive or busy, we search for another colleague who has the same role in order to find someone with green status who is free and can help us. These simple little features became common also in other software applications. As mentioned before, people memorize more by watching and seeing than by reading (Aitken, 1994; Mattingly, 1972). Similarly, also singing a melodic song is easy to memorize, and thus it is easier and faster to learn the underlying text than by simple reading (Dixon, 1991; Ludke et al., 2014). Pictures are easier to recall than words (Paivio et al., 1968). All these interactive actions support information intake with multiple sensual stimuli and therefore enhance the perception, concentration and focus of the learner. However, although watching a video clip supports the learning process far more than a simple reading of a text, it is the repetition of information intake or activity execution that internalizes the gained knowledge. People learn by repeating activities (Morris \& Reid, 1970) and not only from one-time action.

On the other hand, asynchronous yet interactive online courses allow a different and efficient division and scheduling of time slots according to end user's time demands. Furthermore, the whole class is no longer bound to the same pace. Every user can learn at his/her own speed, at any time and in any place. With the omnipresence of internet access, the availability and affordability of technology and nonstop accessibility of the knowledge source, no barriers in terms of space or time limit sharing knowledge with everyone. In addition to this, in the case of e-learning the learner can interrupt the learning process almost anytime and later continue from where he/she last stopped. If necessary, the learner can return to an already explained topic to repeat what he/she has just learned.

Last but not least, the last quadrant depicts ICTs that provide asynchronous and passive interaction such as knowledge bases. These information and knowledge bases are very often perceived to be tedious and boring, as pure reading is often being classified described (Grauert \& Remmert, 2012). Therefore, learning only by reading theoretical articles, particularly in technical sciences, containing several complex equations, is very demanding and perceived as boring. It transfers only explicit knowledge using cognitive perception only by one sense, namely sight. No repetition, quizzes or tasks reduce and suppress the learning process.

Summarizing the four described quadrants, we can assume that the higher the synchronicity, the higher the possibility of transferring tacit knowledge, and simultaneously, the higher the active interaction demand, the higher the learning efficiency, memorization and comprehension by the learner. Considering these aspects, business organizations should try to use whenever possible those current ICTs that have high active interactive approach in order to support the learning process of their employees as much as possible. Both synchronous (transferring also tacit knowledge) and asynchronous mode (efficiently using time) may assure efficient knowledge transfer and management when the ICT conveyors of the knowledge to be shared and transferred are wisely chosen. Every single case should be evaluated properly in order to select the most suitable ICT platform and devices based on the demands of the learning group and the features of available technology. It is important to revise the integrated tools on a regular basis to integrate innovative technologies with higher learning efficiency if possible. Technology evolves very fast and new innovations emerge daily.

\section{Conclusions}

There are currently available various analyses and investigations based on several aspects of knowledge management, such as its relationship with national cultures (Brunet-Thornton \& 
Bureš, 2010). The main objective of this study is to provide additional classification of existing ICTs used for supporting knowledge management initiatives. It aims to add knowledge to the role of ICTs in the field of knowledge management by reviewing their role in various studies and by discussing current business practice. Individual sections introduce the complexity of knowledge management, applicable to various economic systems (Tučník \& Bureš, 2013; Bureš \& Tučník, 2014), an overview of ICT uses in the field of knowledge management, while the last section provides several different classifications of ICTs according to different criteria.

This paper opens a discussion on appropriate utilization of ICT in knowledge management in organizational structures. It emphasizes that prior knowledge is required before data collection, otherwise it is complicated and often very tedious and demanding to transform data into information and subsequently into knowledge. Moreover, the paper offers three diverse classifications of ICTs used in knowledge management. Results from the first classification reveal that tacit knowledge is mostly transferred by multimedia. Results associated with the second classification show that most technology is based on the World Wide Web or databases. The third classification represents a novel point of view. While the first two classifications present various technologies, the third one focuses on synchronicity and interaction. It should be stressed that synchronicity positively influences independence and flexibility of work. On the other hand, it negatively affects the time of work and causes delays. Interaction increases the ability to learn by a more intensive inclusion and activity. Thus, this facet of incorporating active end-user engagement can significantly support the internalization of transferred knowledge and increase the efficiency of the learning process.

\section{Acknowledgements}

The support of the FIM UHK Specific Research Project Socio-economic models and autonomous systems 3 is gratefully acknowledged.

\section{ORCID}

Marek Zanker (D) https://orcid.org/0000-0002-2745-4868

Vladimír Bureš (D) https://orcid.org/0000-0001-7788-7445

\section{References}

Aitken, S. C. (1994). l'd rather watch the movie than read the book. Journal of Geography in Higher Education, 18(3), 291-307. https://doi.org/10.1080/03098269408709269

Alavi, M., \& Leidner, D. (1999). Knowledge Management Systems: Issues, Challenges, and Benefits. Communications of the Association for Information Systems, 1, 1-37. https://doi.org/10.17705/1CAIS.00107

Alavi, M., \& Leidner, D. E. (2001). Review: Knowledge Management and Knowledge Management Systems: Conceptual Foundations and Research Issues. MIS Quarterly, 25(1), 107-136. https://doi.org/10.2307/3250961

Aldrich, C. (2005). Learning by doing: A comprehensive guide to simulations, computer games, and pedagogy in e-learning and other educational experiences (1st ed.). Pfeiffer.

Alfonso-Cendon, J., Fernandez-de-Alba, J.M., Fuentes-Fernandez, R., \& Pavon, J. (2016). Implementation of context-aware workflows with multi-agent systems. Neurocomputing, 176(SI), 91-97. https://doi.org/10.1016/j.neucom.2014.10.098

Al-Rodhan, N. R. F. (2011). Information and Communications Technology (ICT). In J. Zielonka \& O. Anastasakis (Eds.), The Politics of Emerging Strategic Technologies (pp. 18-46). Palgrave Macmillan UK. https://doi.org/10.1057/9780230304949 3 
Babajani-Vafsi, S., Nouri, J.M., Ebadi, A., \& Zolfaghari, M. (2019). Factors Influencing the Participation of Nurses in Knowledge-Sharing Within Mobile Instant Messaging Based Virtual Communities of Practice: A Qualitative Content Analysis. Advances in Medical Education and Practice, 10, 897-905. https://doi.org/10.2147/AMEP.S222779

Battistutti, O.S., \& Bork, D. (2017). Tacit to explicit knowledge conversion. Cognitive Processing, 18, 461-477. https://doi.org/10.1007/s10339-017-0825-6

Borkowski, M., Fdhila, W., Nardelli, M., Rinderle-Ma, S., \& Schulte, S. (2019). Event-based failure prediction in distributed business processes. Information Systems, 81, 220-235. https://doi.org/10.1016/j.is.2017.12.005

Boluki, S., Eshafani, M.S., Qian, X., \& Dougherty, E.R. (2017). Incorporating biological prior knowledge for Bayesian learning via maximal knowledge-driven information priors. BMC Bioinformatics, 18, article number 552. https://doi.org/10.1186/s12859-017-1893-4

Brunet-Thornton, R., \& Bureš, V. (2012). Meeting Czech Knowledge Management Challenges Head-On: KMBe. At-It. In M. Khosrow-Pour (Ed.) Organizational Learning and Knowledge: Concepts, Methodologies, Tools and Applications (pp. 1596-1622). IGI Global.

Bureš, V., \& Tučník, P. (2014). Complex agent-based models: application of a constructivism in the economic research. Economics and Management, 17(3), 152-168. http://doi.org/10.15240/tul/001/2014-3-012

Cherbakov, L., Galambos, G., Harishankar, R., Kalyana, S., \& Rackham, G. (2005). Impact of service orientation at the business level. IBM Systems Journal, 44(4), 653-668. https://doi.org/10.1147/sj.444.0653

Chierici, R., Mazzucchelli, A., Garcia-Perez, A., \& Vrontis, D. (2019). Transforming big data into knowledge: the role of knowledge management practice. Management Decision, 57(8), 1902-1922. https://doi.org/10.1108/MD-07-2018-0834

Chinta, R., \& Das, S. (2005). Application server message logging (United States Patent No. US6879995B1). https://patents.google.com/patent/US6879995/en

Chung, K.C., \& Liang, S.W.J. (2020). An empirical study of social network activities via social internet of things (SloT). IEEE Access, 8, 48652-48659. https://doi.org/10.1109/ACCESS.2020.2978151

Chuvakin, A., \& Peterson, G. (2010). How to Do Application Logging Right. IEEE Security \& Privacy Magazine, 8(4), 82-85. https://doi.org/10.1109/MSP.2010.127

Constantinescu, C.L., Francalanza, E., \& Matarazzo, D. (2015). Towards knowledge capturing and innovative human-system interface in an open-source factory modelling and simulation environment. Procedia CRIP, 33, 23-28. https://doi.org/10.1016/j.procir.2015.06.006

Costa, B., Das, C. P., \& Kepner, W. C. (2000). Network management event storage and manipulation using relational database technology in a data warehouse (United States Patent No. US6138121A). https://patents.google.com/patent/US6138121/en

Dávideková, M., \& Hvorecky, J. (2017). ICT collaboration tools for virtual teams in terms of the SECI model. International Journal of Engineering Pedagogy, 7(1), 95-116. https://doi.org/10.3991/ijep.v7i1.6502

Dávideková, M., \& Greguš, M. (2016). Software Application Logging: Aspects to Consider by Implementing Knowledge Management. In Proceedings of the 2nd International Conference on Open and Big Data (pp. 102-107). IEEE. https://doi.org/10.1109/OBD.2016.22

Dávideková, M., Mjartan, M., \& Greguš, M. (2017). Utilization of Virtual Reality in Education of Employees in Slovakia. Procedia Computer Science, 113, 253-260. https://doi.org/10.1016/j.procs.2017.08.365

Dávideková, M., Greguš, M., Zanker, M., \& Bureš, V. (2020). Synchronicity and Interaction Perspective on Knowledge Management Initiatives. In Proceedings of the International scientific conference Hradec Economic Days 2020, (pp. 77-84). University of Hradec Kralove. http://doi.org/10.36689/uhk/hed/2020-01$\underline{009}$

Desouza, K. C. (2003). Barriers to effective use of knowledge management systems in software engineering. Communications of the ACM, 46(1), 99-101. https://doi.org/10.1145/602421.602458

Dixon, B. (1991, January). Learning by Singing. https://files.eric.ed.gov/fulltext/ED356939.pdf

DuFour, R., Eaker, R., \& Many, T. (2006). Learning by doing: A handbook for professional learning communities at work (1st ed.). Solution Tree.

Farrasis, A., Mazzoleni, A., Devalle, A., \& Couturier, J. (2019). Big data analytics capabilities and knowledge management: impact on firm performance. Management Decision, 57(8), 1923-1936.

https://doi.org/10.1108/MD-07-2018-0825 
Foray, D., \& Lundvall, B.-A. (1998). The Knowledge-Based Economy: From the Economics of Knowledge to the Learning Economy. In D. Neef, G. A. Siesfeld \& J. Cefola (Eds.) The Economic Impact of Knowledge (pp. 115-121). Elsevier. https://doi.org/10.1016/B978-0-7506-7009-8.50011-2

Goëau, H., Vignau, C., Barthélémy, D., Boujemaa, N., Bonnet, P., Joly, A., Affouard, A., Bakic, V., Barbe, J., Dufour, S., Selmi, S., \& Yahiaoui, I. (2014). PI@ntNet Mobile 2014: Android port and new features. In Proceedings of International Conference on Multimedia Retrieval (pp. 527-528). ACM. https://doi.org/10.1145/2578726.2582618

Gonçalves, P., Ferreira, L., Gonçalves, J., Putnik, G. D., \& Cruz-Cunha, M. M. (2014). Direct Communication versus Virtual Communication in Virtual Teams. Procedia Technology, 16, 3-10. https://doi.org/10.1016/j.protcy.2014.10.062

Grauert, H., \& Remmert, R. (2012). Coherent analytic sheaves (265th ed.). Springer Science \& Business Media.

Han, J., Kamber, M., \& Pei, J. (2012). Data mining: Concepts and techniques (3rd ed.). Elsevier.

Hendriks, P. H. J. (2001). Many Rivers to Cross: From Ict to Knowledge Management Systems. Journal of Information Technology, 16(2), 57-72. https://doi.org/10.1080/02683960110054799

Hidalgo Pérez, M. A., O’Kean Alonso, J. M., \& Rodríguez López, J. (2016). Labor demand and ICT adoption in Spain. Telecommunications Policy, 40(5), 450-470. https://doi.org/10.1016/j.telpol.2015.07.004

Hroník, F. (2007). Rozvoj a vzdělávání pracovníků. Grada.

Huysman, M., \& de Wit, D. (2004). Practices of managing knowledge sharing: Towards a second wave of knowledge management. Knowledge and Process Management, 11(2), 81-92. https://doi.org/10.1002/kpm.192

Inmon, W. H. (2005). Building the data warehouse (4th ed). Wiley.

Jarmooka, Q., Fulford, R.G., Morris, R., \& Barratt-Pugh, L. (2020). The mapping of information and communication technologies, and knowledge management processes, with company innovation. Journal of Knowledge Management, ahead-of-print, preprint available. https://doi.org/10.1108/JKM-01-2020-0061

Johannessen, J.-A., Olaisen, J., \& Olsen, B. (2001). Mismanagement of tacit knowledge: The importance of tacit knowledge, the danger of information technology, and what to do about it. International Journal of Information Management, 21(1), 3-20. https://doi.org/10.1016/S0268-4012(00)00047-5

Jorgenson, D. W., \& Vu, K. M. (2016). The ICT revolution, world economic growth, and policy issues. Telecommunications Policy, 40(5), 383-397. https://doi.org/10.1016/j.telpol.2016.01.002

Kluza, K., \& Nalepa, G. (2019). Formal model of business processes integrated with business rules. Information Systems Frontiers, 21, 1167-1185. https://doi.org/10.1007/s10796-018-9826-y

Krötzsch, M., \& Vrandecic, D. (2009). Semantic Wikipedia. In A. Blumauer \& T. Pellegrini (Eds.), Social Semantic Web (pp. 393-421). Springer. https://doi.org/10.1007/978-3-540-72216-8 19

Kumar, R. R., Stauvermann, P. J., \& Samitas, A. (2016). The effects of ICT* on output per worker: A study of the Chinese economy. Telecommunications Policy, 40(2-3), 102-115. https://doi.org/10.1016/j.telpol.2015.06.004

Levin, D. Z., \& Cross, R. (2004). The Strength of Weak Ties You Can Trust: The Mediating Role of Trust in Effective Knowledge Transfer. Management Science, 50(11), 1477-1490. https://doi.org/10.1287/mnsc. 1030.0136

Liao, C.N., \& Kao, H.P. (2014). A QFD approach for cloud computing evaluation and selection in KMS: a case study. International Journal of Computational Intelligence Systems, 7(5), 896-908. https://doi.org/10.1080/18756891.2014.960233

Lin, D., Liang, Q., Xu, Z., Li, R., \& Xie, W. (2008). Does knowledge management matter for information technology applications in China? Asia Pacific Journal of Management, 25(3), 489-507. https://doi.org/10.1007/s10490-008-9087-2

Linde, C. (2001). Narrative and social tacit knowledge. Journal of Knowledge Management, 5(2), 160-171. https://doi.org/10.1108/13673270110393202

Ludke, K. M., Ferreira, F., \& Overy, K. (2014). Singing can facilitate foreign language learning. Memory \& Cognition, 42(1), 41-52. https://doi.org/10.3758/s13421-013-0342-5

Maier, R., \& Hädrich, T. (2011). Knowledge management systems. In D. Schwartz \& D. Te'eni (Eds.) Encyclopedia of Knowledge Management (2nd ed.) (pp. 779-790). IGI Global.

Marty, R. (2011). Cloud application logging for forensics. In Proceedings of the 2011 ACM Symposium on Applied Computing (pp. 178-184). ACM. https://doi.org/10.1145/1982185.1982226 
Mattingly I. G. (1972). Reading, the linguistic process, and linguistic awareness. In Language by Ear and by Eye (pp. 133-147). MIT Press.

Morris, P., \& Reid, R. (1970). The repeated use of mnemonic imagery. Psychonomic Science, 20(6), 337-338.

Nancy, W., Parimala, A., \& Livingston, L.M.M. (2020). Advanced teaching pedagogy as innovative approach in modern education system. Procedia Computer Science, 172, 382-288. https://doi.org/10.1016/i.procs.2020.05.059

Nguyen, T., \& Burgess, S. (2014). A case analysis of ICT for knowledge transfer in small businesses in Vietnam. International Journal of Information Management, 34(3), 416-421. https://doi.org/10.1016/j.ijinfomgt.2014.02.009

Nonaka, I., \& von Krogh, G. (2009). Perspective-Tacit Knowledge and Knowledge Conversion: Controversy and Advancement in Organizational Knowledge Creation Theory. Organization Science, 20(3), 635-652. https://doi.org/10.1287/orsc. 1080.0412

O'Leary, D. E. (1998). Knowledge-Management Systems: Converting and Connecting. IEEE Intelligent Systems and Their Applications, 13(3), 30-33. https://doi.org/10.1109/MIS.1998.683179

Otčenášková, T., Bureš, V., \& Čech, P. (2011). Conceptual modelling for management of public health in case of emergency situations. In Proceedings of the International Conference on Knowledge Engineering and Ontology Development, (pp. 344-348). https://doi.org/10.5220/0003623503440348

Paivio, A., Rogers, T. B., \& Smythe, P. C. (1968). Why are pictures easier to recall than words? Psychonomic Science, 11(4), 137-138.

Panahi, S., Watson, J., \& Partridge, H. (2012). Social media and tacit knowledge sharing: Developing a conceptual model. World Academy of Science, Engineering and Technology, 64, 1095-1102.

Pavlo, A., Paulson, E., Rasin, A., Abadi, D. J., DeWitt, D. J., Madden, S., \& Stonebraker, M. (2009). A comparison of approaches to large-scale data analysis. In Proceedings of the 35th SIGMOD International Conference on Management of Data (pp. 165-178). ACM. https://doi.org/10.1145/1559845.1559865

Raman, M., Ryan, T., \& Olfman, L. (2005). Designing knowledge management systems for teaching and learning with wiki technology. Journal of Information Systems Education, 16, 311-320.

Rashid, M., Clarke, P.M., \& O'Connor, R.V. (2019). A systematic examination of knowledge loss in open source software projects. International Journal of Information Management, 46, 104-123.

Raudeliuniene, J., \& Davidavicius, S. (2017). A conceptual model of assessment of knowledge transfer to consumer. Business Management and Education, 15(2), 174-195. https://doi.org/10.3846/bme.2017.387

Reddy, G. S., Srinivasu, R., Rao, M. P. C., \& Rikkula, S. R. (2010). Data warehousing, data mining, OLAP and OLTP technologies are essential elements to support decision-making process in industries. International Journal on Computer Science and Engineering, 2(9), 2865-2873.

Selamat, M.H., \& Choudrie, J. (2004). The diffusion of tacit knowledge and its implications on information systems: The role of meta-abilities. Journal of Knowledge Management, 8, 128-139.

Schank, R. C., Berman, T. R., \& Macpherson, K. A. (1999). Learning by doing. In C. M. Reigeluth (Ed.) Instructional-Design Theories and Models: A New Paradigm of Instructional Theory (pp. 161-181). Routledge.

Simon, M. (2013). Support of acquisition of recognition of mushroom images. In Proceedings of CESCG 2013: The 17th Central European Seminar on Computer Graphics (pp. 1-8). CESCG.

Smith, E. A. (2001). The role of tacit and explicit knowledge in the workplace. Journal of Knowledge Management, 5(4), 311-321. https://doi.org/10.1108/13673270110411733

Suneetha, K. R., \& Krishnamoorthi, D. R. (2009). Identifying User Behavior by Analyzing Web Server Access Log File. International Journal of Computer Science and Network Security, 9(4), 327-332.

Takhom, A., Usanavasin, S., Supnithi, T., \& Ikeda, M. (2018). Collaborative Ontology Development Approach for Multidisciplinary Knowledge: A Scenario-Based Knowledge Construction System in Life Cycle Assessment. IEICE Transactions on Information and Systems, E101D(4), 892-900.

Tan, C.F., Wahidin, L.S., Khalil, S.N., Tamaldin, N., Hu, J., \& Rauterberg, G.W.M. (2016). The application of expert systems: a review of research and applications. ARPN Journal of Engineering and Applied Sciences, 11(4), 2448-2453.

Taylor, S. J., Bogdan, R., \& DeVault, M. L. (2015). Introduction to qualitative research methods: A guidebook and resource (4th ed.). John Wiley \& Sons, Inc.

Tučník, P., \& Bureš, V. (2013). Inclusion of complexity: Modelling enterprise business environment by means of agent-based simulation. International Review on Modelling and Simulations, 6(5), 1709-1717. 
Tuomi, I. (1999). Data Is More than Knowledge: Implications of the Reversed Knowledge Hierarchy for Knowledge Management and Organizational Memory. Journal of Management Information Systems, 16(3), 103-117. https://doi.org/10.1080/07421222.1999.11518258

Völkel, M., Krötzsch, M., Vrandecic, D., Haller, H., \& Studer, R. (2006). Semantic Wikipedia. In Proceedings of the 15th International Conference on World Wide Web (pp. 585-594). ACM. https://doi.org/10.1145/1135777.1135863

Wheeler, J., \& Fournier, L. (2001). Working in the Asynchronous Environment: Two Case Studies. Journal of Library Administration, 32(1-2), 425-438. https://doi.org/10.1300/J111v32n01 16

Woo, J.-H., Clayton, M. J., Johnson, R. E., Flores, B. E., \& Ellis, C. (2004). Dynamic Knowledge Map: Reusing experts' tacit knowledge in the AEC industry. Automation in Construction, 13(2), 203-207. https://doi.org/10.1016/j.autcon.2003.09.003

Copyright (c) 2020 by the author(s). Licensee University of Economics, Prague, Czech Republic. This article is an open access article distributed under the terms and conditions of the Creative Commons Attribution License (CC BY), which permits use, distribution and reproduction in any medium, provided the original publication is properly cited, see http://creativecommons.org/licenses/by/4.0/. No use, distribution or reproduction is permitted which does not comply with these terms.

The article has been reviewed. I Received: 22 May 2020 | Accepted: 26 June 2020

Academic Editor: Zdenek Smutny 
